\title{
Considering the Gender of Your Web Audience
}

\author{
JULIE FISHER and ANNEMIEKE CRAIG \\ VictoriaUniversity,Julie.fisher@vu.edu.au, Annemieke.craig@vu.edu.au
}

\begin{abstract}
In using the world wide web as a commerce tool, there is the potential to reach more customers than the traditional shop is able to. With a larger and broader audience, able to access an individual business, careful attention needs to be paid to the design of e-commerce systems and web sites. Designers need to be aware of the issues relating to user preferences. If users do not like a particular site or cannot complete a transaction then they are likely never to return to that site. The preferences of different groups and types of users need to be considered if the maximum audience penetration is to be reached and maintained. A pilot study conducted in Australia suggests that women have different expectations of web sites than men but little empirical work has been reported in the literature on identifying these differences or how they impact on web use.
\end{abstract}

\section{DESIGNING WEB SITES}

Many of the issues surrounding effective web site design are similar to those that relate to the design of any system. The literature describes some of the issues that need to be addressed to encourage users to visit and trade online. There are however, other issues for designers of web sites to consider. In particular the issue of designing for a broad and often unknown audience is relevant. Research to date has not focused on user preferences based on gender. This paper discusses the results of a limited study that suggests that the gender of a user can influence preferences.

The literature discusses the importance of good design. Users are likely to visit the site again if they have had a good experience the first time and have found the information they want [5]. Users will make more use of the 
site and more information will be distributed if it is easily navigated [7]. Users are more likely to make a transaction if the design is effective [9].

White and Manning [9] found that how users reacted to a web site impacted their decision to purchase from that site. Their study did not differentiate between users. To achieve maximum market penetration, businesses using the Internet need to pay attention to the preferences of their audience. Designers need to be aware that women as well as men trade online and women may respond to sites differently.

\section{WOMEN AND THE INTERNET}

Feminist literature argues that technology generally is the domain of men $[2,8]$. This theme is supported through research that indicates a significantly higher percentage of those using the net are men [6]. Spender [8, p.166] suggests that "men have more computers, spend more time with them, and are the dominating presence in cyberspace." In particular, Spender [8] is concerned with the dominance men have over Internet discussion groups. She agues that women are intimated or simply put off participating in discussion groups because they feel excluded. Bautista expands on this idea arguing that "On the Internet, male perspectives and voices dominate over women's, who have neither been taught nor trained to use this medium" [1, p.175].

As more stores offer consumers the opportunity to do the weekly shopping online businesses should not ignore the spending power of women on the Internet. What is attractive and engaging for women in terms of Internet sites should therefore be very important for designers and yet there is little evidence that women's preferences are even understood let alone being taken into account when sites are designed.

\section{METHOD}

The research reported in this paper was a pilot study investigating how decisions are made relating to design of Internet sites. A theoretical model developed from the literature, identifying the main elements in the design of web sites that contribute to effectiveness is presented in Table 1. These elements were used to assess each web site.

Table 1 Key elements in effective web design

\begin{tabular}{|l|l|}
\hline Element & Design issue \\
\hline Information & $\begin{array}{l}\text { Quality of the information [5]. } \\
\text { Quantity of information [9]. }\end{array}$ \\
\hline
\end{tabular}




\begin{tabular}{|l|l|}
\hline & Accessibility [4] \\
\hline Display & $\begin{array}{l}\text { Quality of the display [9]. } \\
\text { The design of the text [9]. } \\
\text { The colours and graphics presented [9]. }\end{array}$ \\
\hline Usability & $\begin{array}{l}\text { Quality and effectiveness of links [4] } \\
\text { Ease of navigation [7] } \\
\text { Ability to complete the task effectively [7]. }\end{array}$ \\
\hline
\end{tabular}

The research required users to complete a series of tasks on selected web sites and to answer questions. The sample size was small, eight sites were investigated by 14 users (seven male, seven female). Each user explored and commented on four sites. The questions required users to respond on a five point scale or to answer Yes/No.

Users were given the sites and tasks to be completed. The sites were all local micro businesses. Two of the sites had the facility to purchase on line. The sites were: florist, jeweller, two reception centres, online green grocers, bicycle shop, motel and a business selling online products for the disabled. The elements identified in Table 1 were used to categorise the users' answers. Another matrix was developed and the answers given by the two groups (male and female) were identified and entered. The qualitative data collected was analysed using a meta matrix [3].

\section{RESULTS}

The 14 users were all tertiary students of different age groups from 18 to 46 years old. Most of the users indicated they were very experienced or had some experience using the Internet. Five of the women and two of the men did not have home access. The female students logged onto the Internet an average of 1.1 hours per day, for male students it was 1.6 hours.

\subsection{Overall reaction to sites}

Users were asked to indicate on a five point scale how they felt about each site. The options were scored 5-Very interested, to 1-Very bored. Chart 1 presents the results of the two groups averaged for each site. The $\mathrm{X}$ axis represents the site number (see Table 2), the $\mathrm{Y}$ axis is the rating. 


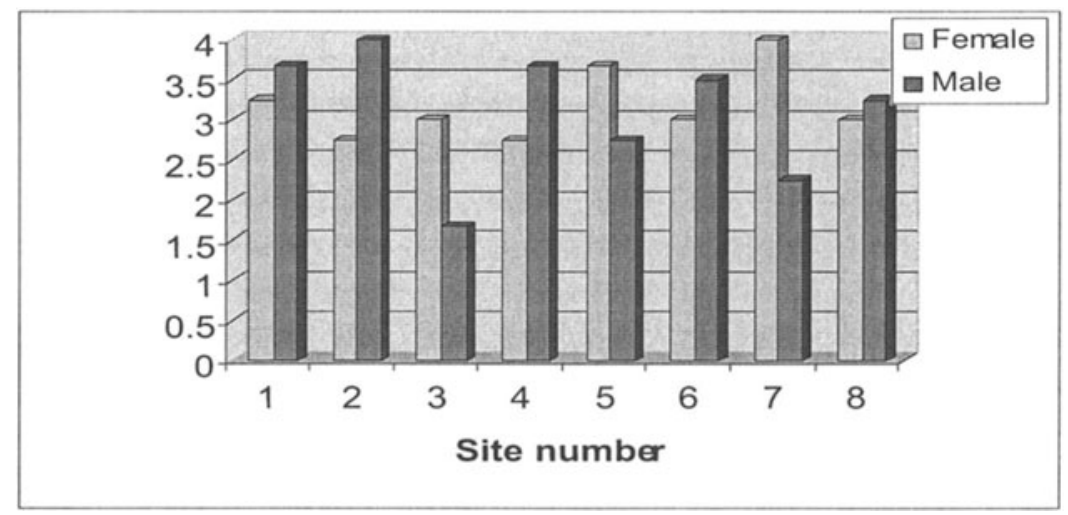

Chart 1 Users' responses to the Web sites

The results suggest male and female users have different web sites preferences. Male users liked the bicycle site and the online green grocers, the female users preferred the one reception centre and the florist.

\section{SUMMARY OF POSITIVE AND NEGATIVE COMMENTS}

A count of the number of positive and negative comments the male and female users made about each of the sites. Table 2 presents the results. $\mathrm{P}=$ Positive, $\mathrm{N}=$ Negative.

Table 2 Positive and negative responses to sites

\begin{tabular}{|l|l|l|l|l|l|}
\hline Site & Task set & \multicolumn{3}{|l|}{ Male } & \multicolumn{2}{|l|}{ Female } \\
\hline & & P & N & P & N \\
\hline 1.Reception Centre 1 & Book birthday party & 12 & 9 & 6 & 16 \\
\hline 2. Bicycle & Purchase bike and organise repairs & 13 & 5 & 9 & 10 \\
\hline 3. Florist & Purchase flowers & 7 & 14 & 7 & 13 \\
\hline 4. Motel & Book a room & 8 & 18 & 11 & 8 \\
\hline 5. Disabled aids & Buy present for disabled child & 11 & 6 & 10 & 1 \\
\hline 6. Jewellers & Buy a watch & 6 & 19 & 8 & 12 \\
\hline 7. Reception Centre 2 & Book birthday party & 3 & 14 & 13 & 2 \\
\hline 8. Green groceries & Buy potatoes and apples & 13 & 7 & 7 & 13 \\
\hline
\end{tabular}

Site 3 was the only site where the number of positive and negative comments was similar between the two groups. Sites $1,4,6,7$ and 8 were quite different in the responses generated between the two groups. Male users disliked Site 6, female users generally liked it. The male users liked the first reception centre and disliked the second, for the female users the reverse was the case. This is broadly consistent with the results presented in Chart 1 relating to the users' reactions. Further analysis follows. 


\subsection{Analysis of user responses}

Following is an analysis of answers given by all users on the individual sites. It is organised under the three key elements from Table 1, these are: quantity and quality of the information, design and quality of the display, usability of the site. It should be noted that the examples presented in the tables represent the broad areas of disagreement between the two groups on a particular site.

\section{QUANTITY AND QUALITY OF INFORMATION}

Users were asked to indicate, how much of the information on each site they read, $5=$ 'All of it' and $1=$ 'None'. Three of the sites, Sites 1, 5, 8 were read more thoroughly by female users. Sites 2 and 5 were read more thoroughly by male users. Female users were more likely to read the information presented than the male users - the average of female users reading sites was 3.7 and for male users it was 3.4.

The users were also asked to indicate the level to which they agreed or disagreed with the statement 'I found all the information I wanted from the web site.' Chart 2 presents the found results averaged for each group.

Chart 2 Quantity of information

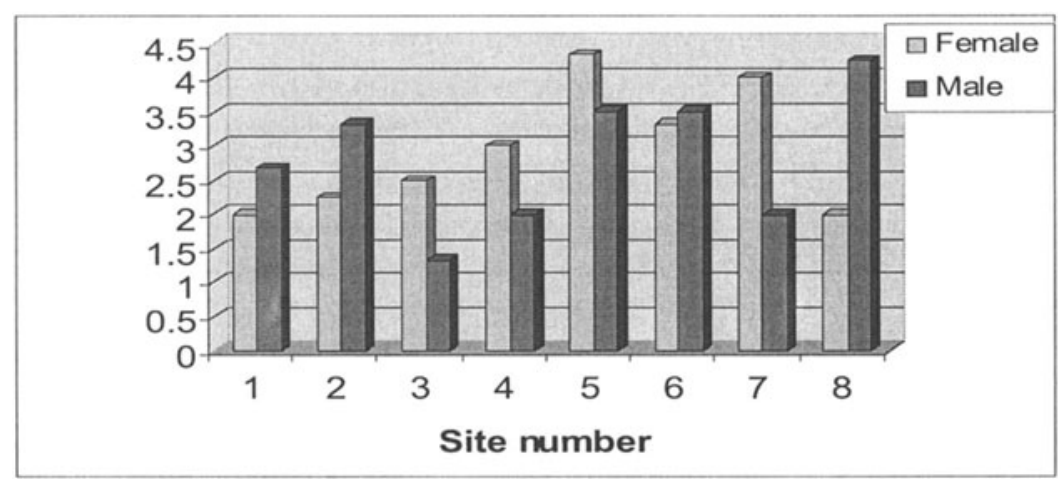

Female users were more satisfied with the information found on Sites 4, 5 and 7. For male users Sites 2 and 8 were sites that provided them with the information they wanted. Table 2 provides examples of the contrasting comments made by the two groups.

Table 2 Examples of information preferences

\begin{tabular}{|l|l|l|}
\hline Site & Male & Female \\
\hline $\begin{array}{l}\text { 1. Reception } \\
\text { Centre 1 }\end{array}$ & $\begin{array}{l}\text { Too much text was the worst } \\
\text { feature of the site } \\
\text { Information was great although a }\end{array}$ & $\begin{array}{l}\text { Information was effective } \\
\text { I would look at the site again for the } \\
\text { update of restoration of the mansion }\end{array}$ \\
\hline
\end{tabular}




\begin{tabular}{|l|l|l|}
\hline 2. Bicycles & little too much text. & if the information was provided. \\
& $\begin{array}{l}\text { Information was very effective } \\
\text { because the icons were at the top of } \\
\text { the page } \\
\text { The information was easy to follow. }\end{array}$ & $\begin{array}{l}\text { I might return, it didn't tell me } \\
\text { prices or a lot of information. } \\
\text { Not a great deal of information or } \\
\text { text. Didn't tell me anything useful. }\end{array}$ \\
\hline 6. Jewellers & $\begin{array}{l}\text { Brief view of the site it was just } \\
\text { information, nice to know - not } \\
\text { interesting enough to enter the site. } \\
\text { Had to read information to continue } \\
\text { and find what you were looking for. }\end{array}$ & $\begin{array}{l}\text { I would come back to the site if } \\
\text { they continually updated history } \\
\text { page on diamonds. } \\
\text { Best feature of the site was the } \\
\text { history of the diamonds }\end{array}$ \\
\hline $\begin{array}{l}\text { 8. Green } \\
\text { grocers }\end{array}$ & $\begin{array}{l}\text { The information was very effective, } \\
\text { a well thought out site. } \\
\text { Information was effective, easy to } \\
\text { read and understand. }\end{array}$ & $\begin{array}{l}\text { I needed more information. } \\
\text { Couldn't find the information } \\
\text { needed to complete tasks, this was } \\
\text { frustrating }\end{array}$ \\
\hline
\end{tabular}

Information was a key issue for female users. The quality and how informative the site appeared was something the female users preferred. They particularly wanted descriptive information and were critical of sites that did not provide enough information. Male users wanted less descriptive information and were critical of sites where there was too much information, they were less interested in reading the text than completing the task.

\section{VISUAL ASPECTS OF THE SITES}

Users were asked to rate on a scale of 1 to 5 the level to which they agreed with the statement 'I found the design of the interface very appealing.' Results are summarised in Chart 3.

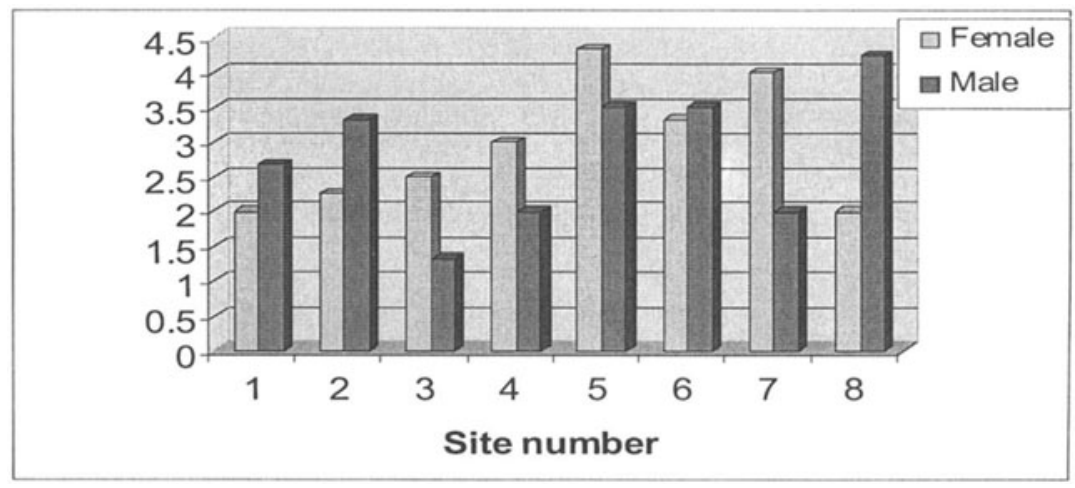

Chart 3 Appeal of the interface design

Table 3 provides examples of the comments made by the two groups on the visual aspects of the sites. 


\begin{tabular}{|c|c|c|}
\hline Site & Male & Female \\
\hline 4. Motel & $\begin{array}{l}\text { Text was not very effective } \\
\text { Fonts could have been larger } \\
\text { Colours hard to read }\end{array}$ & $\begin{array}{l}\text { Layout of text was the best feature } \\
\text { it was easy and attractive to read } \\
\text { Best feature was the colours }\end{array}$ \\
\hline 6. Jewellers & $\begin{array}{l}\text { Graphics: Best features are the } \\
\text { photos of the merchandise. } \\
\text { Text: Too many colours some times } \\
\text { so hard to read } \\
\text { Worst feature was colour of the text } \\
\text { Better if text was readable, colour } \\
\text { of text was a disgrace. } \\
\text { Text was shocking, terrible, } \\
\text { designer should be shot }\end{array}$ & $\begin{array}{l}\text { Graphics: Worst feature, pictures } \\
\text { and graphics } \\
\text { Not that effective because it just } \\
\text { shows the pictures } \\
\text { Text: Background was confusing, } \\
\text { not easy on the eye } \\
\text { The big blocks of yellow writing } \\
\text { were a little hard to follow. } \\
\text { Worst feature was the yellow font }\end{array}$ \\
\hline $\begin{array}{l}\text { 7. Reception } \\
\text { centre } 2\end{array}$ & $\begin{array}{l}\text { Text too cramped, should have been } \\
\text { better spaced out. } \\
\text { Worst thing the boring white } \\
\text { background. } \\
\text { Nice use of white space } \\
\text { Photographs the best thing }\end{array}$ & $\begin{array}{l}\text { White background was boring but } \\
\text { probably the best option } \\
\text { Pictures and presentation good } \\
\text { Font well chosen and layout good. } \\
\text { The text very easy to read, clear, } \\
\text { good layout, good fonts. } \\
\text { Black on white - easy to read }\end{array}$ \\
\hline $\begin{array}{l}\text { 8. Green } \\
\text { grocers }\end{array}$ & $\begin{array}{l}\text { Graphics: Best feature was the get } \\
\text { fresh icon } \\
\text { Looks good } \\
\text { No moving animation but get fresh } \\
\text { character was an appealing logo } \\
\text { Text: Very effective, big enough to } \\
\text { read nicely spaced out on the page } \\
\text { Worst feature was the ugly white } \\
\text { background } \\
\text { Text well displayed }\end{array}$ & $\begin{array}{l}\text { Graphics: Worst feature-the } \\
\text { colour, layout, no pictures were } \\
\text { available of the products. } \\
\text { The green colour was revolting } \\
\text { Pictures cute the getfresh.com.au } \\
\text { delivery man picture } \\
\text { Text: Amount of text was off putting } \\
\text { Text well displayed, easy to read. } \\
\text { Best feature was the large, bold font }\end{array}$ \\
\hline
\end{tabular}

Table 3 Responses to the visual elements of the sites

There were no positive comments from the male users on the motel site yet a number of the female users commented positively on the text and display. One male user made reference to the photographs on the Jeweller's site. This site had many photographs that the female users particularly disliked. The language the male users used to describe the display of the text was very strong compared with the female users.

\section{USABILITY OF THE SITE}

How useable a site is, is an important aspect of web design. Users were asked questions relating to usability. The statement 'The site was easy to use' was presented to users and they were asked the level to which they agreed or disagreed with the statement. Chart 4 presents the results. 


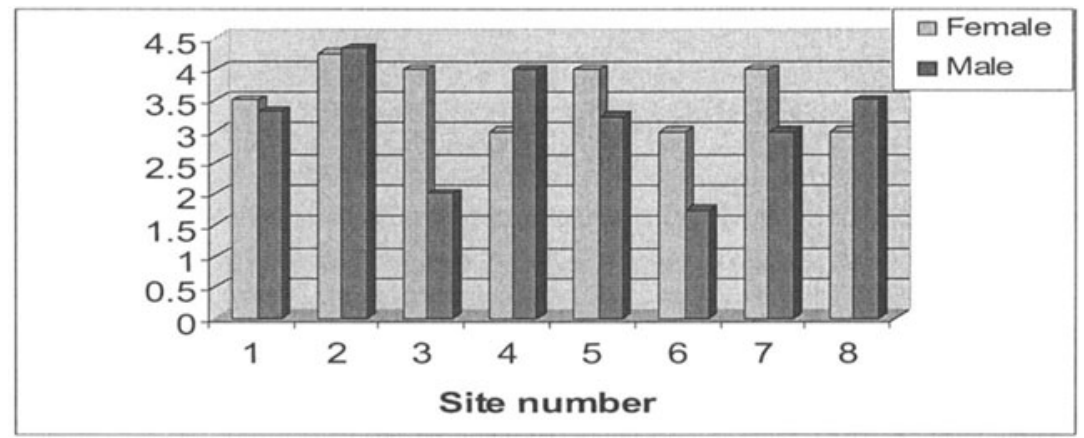

Chart 4 Ease of use of web sites

Site 8 was the site with the greatest difference expressed between the two groups. Male users found this site easier to use than the female users. Female users found Site 5 easier to use. The statement 'It was easy to navigate through the site' was also put to the users with similar results. Table 4 provides an overview of the responses, again comments have been included only for sites where there as a discernible difference between the groups.

Table 4 Users responses to the usability of the sites

\begin{tabular}{|c|c|c|}
\hline Site & Male & Female \\
\hline $\begin{array}{l}2 . \\
\text { Bicycles }\end{array}$ & $\begin{array}{l}\text { Would come back if buying a bike } \\
\text { Best feature - ease of use of icons } \\
\text { Usability was pretty straight forward } \\
\text { Best feature - links to other pages } \\
\text { within site was easy } \\
\text { Come back? If I wanted a bike and } \\
\text { more descriptive information was } \\
\text { provided } \\
\text { I would return to the site if I needed } \\
\text { bike repairs or a bike }\end{array}$ & $\begin{array}{l}\text { Information was good but pictures } \\
\text { flashing was annoying } \\
\text { Worst feature - no prices no online } \\
\text { ordering facilities } \\
\text { No prices no online ordering } \\
\text { Confusion caused by links and } \\
\text { graphics you touch a button image } \\
\text { flashes but it will not go to the page } \\
\text { Tool bar down the side was great } \\
\text { for navigating around the site }\end{array}$ \\
\hline $\begin{array}{l}\text { 8. Online } \\
\text { Green } \\
\text { Grocer }\end{array}$ & $\begin{array}{l}\text { Very friendly feeling } \\
\text { Very easy to use. } \\
\text { Very easy to use, looks good explains } \\
\text { what you need to know Easy to return } \\
\text { to the home page. } \\
\text { Rather easy to explore } \\
\text { Pages flowed and linked correctly } \\
\text { Easy to use and navigate between } \\
\text { pages }\end{array}$ & $\begin{array}{l}\text { Site was slightly confusing would } \\
\text { not come back to the site } \\
\text { Found it confusing I was lost } \\
\text { I wanted to go back to home page } \\
\text { to recheck, it would not let me. } \\
\text { I did not understand where to go. } \\
\text { I couldn't find out how to register } \\
\text { Could not find information needed } \\
\text { to complete tasks, frustrated. }\end{array}$ \\
\hline
\end{tabular}

Site 4 generated comments from both groups on the lack of online booking facilities. Male users found Site 8 easy to use, female users did not. Although there were more negative comments from female users regarding the usability of Site 2, when asked to rate the site on ease of use and how easy it was to navigate the two groups were similar in their responses. 


\section{DISCUSSION AND SUMMARY}

Although the study was small the results suggest that there are differences in the perceptions and expectations male and female users bring with them when exploring Internet sites. Four elements of web sites, where there was a difference between the two groups, are presented in Chart 5. The visual elements of the site, the quality of the information, how interesting they found the site, the usability of the site.

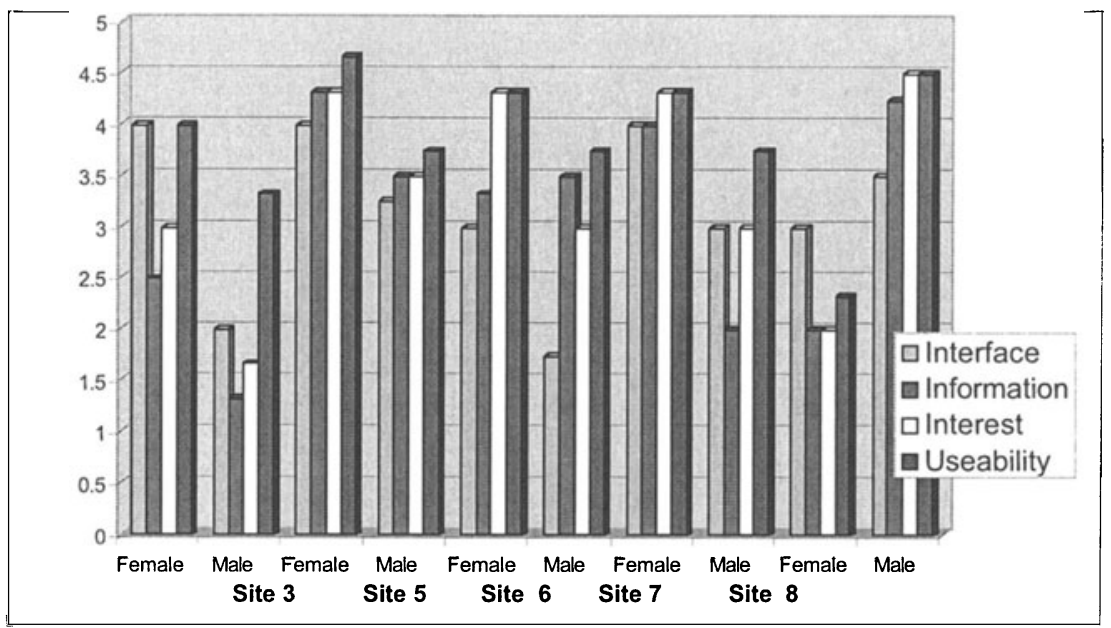

Chart 5 Summary of responses to five web sites

Female users had a more positive response to all the elements of 4 web sites than the male users. Site 8 was the exception, the male users really liked the site but not the women.

Chart 5 suggests that generally the female users rated all of the four elements of the web sites investigated higher than the male users with the exception of one site.

The key issues to emerge from this research were:

Women appreciate effective information on web sites.

Women are more likely to read all the information on a site.

The style of the text and how it is displayed is also important for women.

Women find graphics and pictures less important and of less interest.

\section{LIMITATIONS AND FURTHER WORK}

The major limitation to this study was the size of the group of users. The second limitation was the selection of sites with one site (the Florist) is more 
likely to appeal to women. The results suggest that further research is needed involving a larger group of users and a greater range of sites.

\section{CONCLUSION}

Using the Internet for marketing and e-commerce is increasingly important for business. Understanding the audience and how to design web sites to meet the needs of the audience is important if a business is to be successful online. Despite this, there is little work that specifically addresses women's (or men's) preferences and reactions to web site design. Both women and men earn money and shop therefore, businesses and designers of web sites who ignore this possibly do so to the peril of their business.

\section{REFERENCES}

1. Bautista, R. (1999). Staking their Claim. Women@Internet - Creating New Cultures in Cyberspace. W. Harcourt. New York, Zed Books. 1: 173-183.

2. Inayatullah, S. and I. Milojevic (1999). Exclusion and Communication in the Information Era. Women@Internet - Creating New Cultures in Cyberspace. W. Harcourt. New York, Zed Books. 1: 76-87.

3. Miles, M. B. and M. A. Huberman (1994). Qualitative Data Analysis. London, Sage.

4. Moeller, E. (1997). Designing a Winning (and Usable) Web Site. Crossroads in Communication, IPCC 97, Salt Lake City, Utah, USA, IEEE Professional Communication Society.

5. Salam, A., H. Rao, et al. (1998). "Content of Corporate Web Pages as Advertising Media." Communications of the ACM 41(3): 76-77.

6. Senjen, R. and J. Guthrey (1996). The Internet for Women. Melbourne, Spinifex.

7. Silker, C. and L. Gurak (1996). "Technical Communication in Cyberspace: Report of a Qualitative Study." Journal of the Society for Technical Communication 43(3): 357-368.

8. Spender, D. (1995). Nattering on the Net - Women, Power and Cyberspace. Melbourne, Spinifex.

9. White, G. and B. Manning (1998). “Commercial WWW Site Appeal: How Does it Affect Online Food and Drink Consumers' Purchasing Behavior?" Internet Research: Electronic Networking Applications and Policy. http://www.emerald-library.com/brev/17208ad1.htm. 